\title{
Instrumen Snare Drum Produksi Al Custom Drum Di Kediri Jawa Timur Dalam Tinjauan Organologi dan Menejerial Pemasaran
}

\author{
Lucky Hermansyah \\ Program Studi Seni Musik Fakultas Bahasa dan Seni Universitas Negeri Surabaya \\ Email: luckyhermansyah1996@gmail.com
}

\begin{abstract}
Abstrack: Al Custom Drum is a musical instrument production house that is inhabited by several drum musical instrument craftsmen (Homemaker) which was founded by Alfin Duma in Minggiran Village, Kediri Regency, East Java. Material selection is an important thing to do as a start to get quality ingredients. So in the selection of Al Custom Drum production house materials do several stages, namely the stage of cutting wood, the stage of cutting the snare drum material, and the stage of drying the material. Drying at a temperature of $45-70 \mathrm{C}$ is used so that the wood does not burn or burn because this process is only intended to give a brown color and slightly reduce the water content. This is also done by the $\mathrm{Al}$ Custom Drum production house in scraping wood using an oven and with a temperature of 70 degrees to reduce water content and also gives a red color to the wood because the results of the oven Organology from the instrument Snare Drumproduction Al Custom Drum uses wood material local mahogany with the production process from the initial stage to the end with an estimated time of 18 days of work to then become a Snare Drum instrument that can be played, local wood material with the type of mahogany chosen creates the character of the instrument Snare Drum that is loud (crisp) and does not break (ulem) Al Custom Drum production also has a distinctive feature of its production which is the boring angle which is carried out during the lathe process, taking into account the manufacture with a certain angle makes it different from other production houses.
\end{abstract}

Keyword: Organology, snare drum Al Custom Drum, Managerial Production

\begin{abstract}
Abstrak: Al Custom Drum merupakan rumah produksi alat musik yang dihuni oleh beberapa pengrajin alat musik Drum (Homemaker) yang didirikan oleh Alfin Duma di Desa Minggiran Kabupaten Kediri Jawa Timur. Pemilihan bahan merupakan hal yang penting dilakukan sebagai awal untuk mendapatkan bahan yang berkualitas. Sehingga dalam pemilihan bahan rumah produksi Al Custom Drum melakukan beberapa tahapan, yaitu tahap pemotongan kayu, tahap pemotongan bahan snare drum, dan tahap pengeringan bahan. Pengeringan dengan suhu 45-70C di gunakan agar kayu tidak menjadi gosong atau terbakar karena proses pengentin ini hanya bertujuan untuk memberikan warna coklat dan sedikit mengurangi kadar air. Hal ini juga yang di lakukan oleh rumah produksi Al Custom Drum dalam mengeringan kayu dengan menggunakan oven serta dengan suhu 70 derajat untuk mengurangi kadar air dan juga memberikan warna merah pada kayu karena hasil oven Organologi dari instrument alat musik Snare Drumproduksi Al Custom Drum menggunakan bahan kayu local mahogany dengan proses produksi dari tahap awal hingga ahir dengan estimasi waktu 18 hari pengerjaan untuk kemudian menjadi instrument Snare Drumyang sudah dapat dimainkan, bahan kayu local dengan jenis mahogani yang dipilih menciptakan karakter instrumen Snare Drumyang nyaring (renyah) dan tidak pecah (ulem) Rumah produksi Al Custom Drum juga memiliki chiri khas dari produksinya yaitu sudut boring yang dilakukan pada saat proses bubut, dengan mempertimbangkan pembuatan dengan sudut tertentu menjadikanya berbeda dari rumah produksi yang lain.
\end{abstract}

KataKunci: Organologi, snare drum Produksi Al Custom Drum, Managerial Produksi

\section{PENDAHULUAN}

Seni musik merupakan sebuah kesenian yang berkaitan dengan perihal bunyi-bunyian yang memiliki emosional dalam memainkanya, serta ekspresi dalam menyajikanya. Pernyataan tersebut di perkuat oleh Dwiki Dharmawan yang juga mengatakan, musik berasal dari suara, suara itu sendiri adalah suatu partikel dari semua 
elemen yang membentuk dunia ini (2014:1). Sedangkan Suka Hardjana yang juga mengatakan bahwa bunyi, suara sebagai materi terpenting daripada musik baru dapat memenuhi fungsinya sebagai bagian atau materi musik apabila ia telah mengalami modifikasi yang berhubugan dengan tingkat kesadaran dan daya kreasi manusia, (2018:15). Bunyi yang diekspresikan dengan melibatkan pengetahuan maka kemudian disebut sebagai nada, yaitu dengan melalui proses ditentukannya jumlah getarannya melalui digunakan sajian baik musik klasik ataupun musik modern. Sedangkan salah satu alat musik yang menarik dan sering muncul dalam sajian baik musik klasik ataupun musik modern dewasa ini adalah alat musik jenis percusi yaitu alatmusikDrum Alat musik Drum merupakan salah satu instrument musik yang tergolong dalam alat musik Idiophone atau cara memainkannya dengan teknik dipukul menggunakan Stik Drum. Alat musik Drum terdiri dari beberapa komponen alat yaitu alat musik Tom-tom Drum, Hi-hat Drum, Cymbal Drum, Floor Drum, Bass Drum dan Snare Drum. Alat ini berfungsi sebagai penegas rytme dalam sajian tempo. Sedangkan dalam musik modern misalakan jenis musik Jazz, penggunaan alat musik drum ini tidak hanya sebagai penegas tempo namun juga sebagai ajang ekspresi musical (improvisation) pelaku seninya.

Alat musik Drum yang lahir dengan berbagai nama (label merk) produk seperti Tama, Sonor, Sakae, Pearl dan juga masih banyak lagi merupakan para produsen yang hingga sekarang mampu bersaing dalam pasar industri alat Drum dengan beragam kwalitas ataupun harga. Kwalitas alat musik yang menentukan karakter suara dipengaruhi dengan bahan-bahan tertentu yang digunakan sebagai organologi dari instrument Drum oleh para produsen. Hal inilah yang kemudian ikut membentuk selera para pemusik untuk memilih instrument yang diinginkan. Bahkan terjadi pula para pemusik kemudian menata instrument Drum dengan beberapa pilihan komponen instrument Drum sesuai dengan selera yang diiinginkan. Misalkan saja untuk komponen bagian instrumen Bass Drum memilih yang diproduksi oleh Tama, namun untuk komponen bagian instrument Tomtom lebih memilih alat yang diproduksi oleh Pealr, dan seterusnya. Hal inilah juga yang akhirnya ikut memicu munculnya beberapa produsen alat musik Drum dari para pemain instrumen Drum secara mandiri (homemaker). pengukuran getaran dihasilkan dari sumber bunyi. Dan ditinjau dari cara membunyikan, maka bunyi kemudian dapat diklasifkasikan. Dalam Pono Banoe, Mahillom-Sac-Vom Hornbostel mengklasifikasikan alat musik sebagai sumber bunyi menjadi lima kelompok, yaitu : Idiophone (dipukul), Aerophone (ditiup), Chordophone (digesek), Membranophone (dipukul dengan telapak tangan) dan Electrophone (ditekan) (2003:222). Pengklasifikasian alat musik yang Alat musik Drum yang diproduksi oleh para pelaku instrument Drum merupakan aplikasi dari selera musikal dan pengetahuan para pelaku itu sendiri, baik kemudian digunakan untuk kebutuhan pribadi ataupun juga meluas kemudian melayani pemesanan. Hal ini oleh karena penyebar luasan alat yang diproduksi kepada sesama pelaku musik serta pelayanan terhadap selera pembeli. Sehingga kemudian banyak juga para pelaku instrument Drum lebih menikmati untuk menjadi produsen alat musik Drum.

Produksi dari alat musik Drum yang dibuat merupakan langkah dalam melayani permintaan lanngsung dari pemusik. Selain hal kwalitas dan karakter suara, biasanya juga disebabkan oleh karena harga dari alat musik yang masih terjangkau atau lebih murah dari harga alat musik hasil pabrikan. Sehingga para produsen kalangan pengrajin kemudian memilih untuk membuat alat dengan menggunakan bahan-bahan lokal atau harga murah dan mudah didapatkan. Hal inilah yang sering dilakukan oleh rumah produksi (homemaker) sekarang ini. Salah satu rumah produksi yang masih menggunakan bahan local untuk produksi alat musik Drum adalah rumah produksi Al Custom di Kabupaten Kediri.

Rumah produksi Al Custom Drum didirikan oleh Alfin Duma (29 tahun) dengan fokus membuat alat musik Drum yang menggunakan bahan kayu lokal yaitu kayu Mahogani, kayu Meranti, kayu Nangka, Rose Wood dan kayu Kalilongan. Namun khusus untuk membuat alat Snare Drum, rumah produksi ini focus dengan menggunakan bahan kayu Mahogani. Selain dapat mengahasilkan alat musik yang mempunyai kwalitas baik karakter suara ataupun tampilannya, bahan kayu ini juga sangat mudah didapatkan di sekitaran Kabupaten Kediri.

Alfin Duma selaku produsen dari $A l$ Custom Drummemaparkan bahwa alat Snare Drumyang diproduksi mengutamakan kualitas dari bahan kayu Mahogani yang pertimbangakan dari segi umur kayu, pengolahan tingkat kadar air 
pada kayu, juga proses pembuatan yang detail. Karena pencapaian kualitas suara yang di hasilkan akan berdasarkan bahan kayu yang sedikit memiliki kadar air dan tingkat kekeringan yang cukup. Pemilihan kayu Mahogani sebagai bahan utama dari Snare Drumoleh karena penemuan dalam memproses kayu dengan teknik tertentu atau khusus. Sehingga dapat menghasilkan suara yang dapat di gunakan di semua genre musik. Kalau melalui proses yang baik, kayu Mahogani merupakan mapelnya Indonesia (Alfin Duma: 12 Feb 2020).

Al Custom Drum merupakan rumah produksi alat musik yang dihuni oleh beberapa pengrajin alat musik Drum (Homemaker) yang didirikan oleh Alfin Duma di Desa Minggiran Kabupaten Kediri Jawa Timur. Alat musik Snare Drumyang diproduksi oleh Al Custom memiliki ciri khusus, yaitu memanfaatkan keutuhan kayu tanpa potongan sedikitpun atau sering di sebut dengan true solid wood. Langkah seperti ini yang kemudian juga menjadikan banyak kalangan baik pemusik ataupun rumah produksi alat musik lainnya mengenal ciri khas alat yang diproduksi oleh Al Custom. Ataupun kemudian membedakan dengan alat Snare Drumpada umumnya, yang menggunakan bahan kayu tidak utuh atau kayu yang sudah melalui proses pemotongan tipis seperti triplek yang kemudian di bentuk menjadi Snare Drumatau biasa di sebut dengan Ply Wood. penelitian ini merupakan ilmu untuk menambah wawasan terhadap proses pembuatan Snare Drumlokal dengan merk Al Custom Drumyang di produksi di daerah Kediri Jawa timur, selain itu hasil dari wawancara dapat di jadikan acuan untuk proses penelitian selanjutnya.

\section{HASIL PENELITIAN DAN PEMBAHASAN Organologi Instrumen Snare DrumProduksi Al Custom Drum}

Teori organologi menerangkan tentang telaah karekter suara dalam satu alat musik berdasarkan dari bahan yang di gunakan dalam alat musik tersebut. Hal ini selaras dengan proses pembuatan alat musik Snare Drum produksi oleh Al Custom Drum yaitu mempertimbangkan capaian karakter suara untuk dapat digunakan bermain dalam lintas genre musik, dengan menggunakan bahan kayu lokal jenis kayu Mahogani. Sehingga untuk mengkaji organologi dari alat musik Snare Drum produksi Al Custom Drum meliputi: pemilihan bahan, proses pembuatan, proses finishing. Berikut penjabaran kajian organologi instrument Snare Drumproduksi Al Custom Drum:

\section{Pemilihan bahan Instrumen Snare Drum produksi Al Custom Drum}

Pemilihan bahan merupakan hal yang penting dilakukan sebagai awal untuk mendapatkan bahan yang berkualitas. Sehingga dalam pemilihan bahan rumah produksi $A l$ Custom Drum melakukan beberapa tahapan, yaitu tahap pemotongan kayu, tahap pemotongan, dan tahap pengeringan bahan. Berikut penjabaranya:

\section{Tahap pemilihan kayu}

Bahan kayu yang dipilih oleh Alfin merupakan jenis kayu local yaitu jenis kayu Mahogani yang berdasarkan dari usia kayu dan kadar kandungan air di dalam kayu. Hal ini dengan pertimbangan memilih kualitas bahan yang baik akan menciptakan kualitas instrument yang baik pula.

Alfin memiliki pengetahuan tentang jenis kayu Mahogani yang tumbuh dengan baik dan hingga berusia kisaran 60-100 tahun akan memiliki kisaran ukuran diameter $60 \mathrm{~cm}$, memiliki kandungan kadar air kisaran $57.06 \%$ w. serta memiliki ketinggian kisaran $34 \mathrm{M}$. Sehingga akan menjadi langkah efektif pula ketika digunakan sebagai bahan dari beberapa jenis instrument yang akan diproduksi, antara lain instrument Bass Drum berukuran 18 x 14 $\mathrm{cm}$, instrumen Flore Tom ukuran $16 \times 15 \mathrm{~cm}$, instrument Tom-Tom ukuran $14 \times 13 \mathrm{~cm}$ serta Snare Drumukuran 14 x $7 \quad \mathrm{~cm}$. Selain efektifitas bahan, juga dengan kayu utuh dengan ukuran kayu dan kadar air, hal ini relevan dengan data berdasarkan pertumbuhan kayu mahoni yang pada usia 6 bulan memiliki pertumbuhan rata- rata $6.66 \mathrm{~mm}$ sehingga membutuhkan waktu sekitar 60 tahun untuk mencapai diameter $60 \mathrm{~cm}$ serta memiliki kadar air $57.06 \%$ (Raden mutia inayah azzahra 2018) kayu ini yang kemudian di gunakan oleh $\mathrm{Al}$ Custom dalam standar bahan yang akan di gunakan dengan mempertimbangkan aspek diamer dan kadar air.Berikut gambar dari kayu yang dipilih oleh Al Custom Drum:

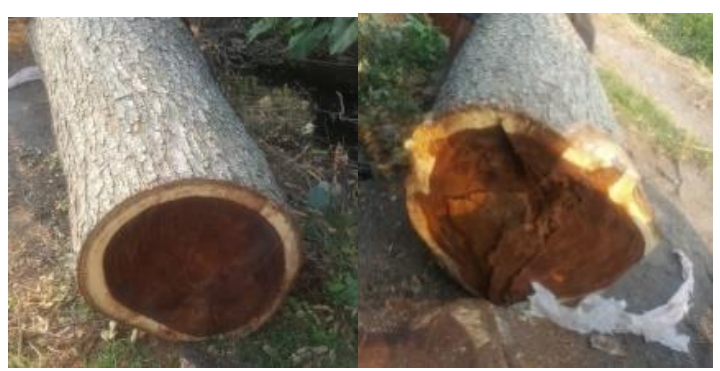

Foto 1. Kayu yang di pilih Al Custom Drum (dok.2020. Alfin Duma Felanda) 


\section{Pemotongan Kayu}

Proses pemotongan kayu yang di lakukan oleh Al Custom di bagi menjadi dua yaitu pemotongan awal dan tahap selanjutnya, untuk pemotoangan awal yang di lakukan hanya memotong dari pohon dan kemudian di potong menjadi beberapa bagian, dalam proses pemotongan ini kayu akan di jadikan beberapa jenis ukuran snare mulai dari $14,12,10$, dan 8 proses pengugunaan gergaji mesin sangat penting dalam prses pemotongan kayu , karena tingkat efisiensi tan memudahkan dalam memotong kayu.

Pemotongan kayu yang di lakukan secara simetris karena pemotongan kayu yang tidak simetris akan mempengaruhi dari tinggi sebuah snare yang akan di buat, pemotongan yang di lakukan harus lurus dan seimbang antar tebal diameter lingkaranya. Berikut gambar bahan kayu Mahogani yang sudah disiapkan:
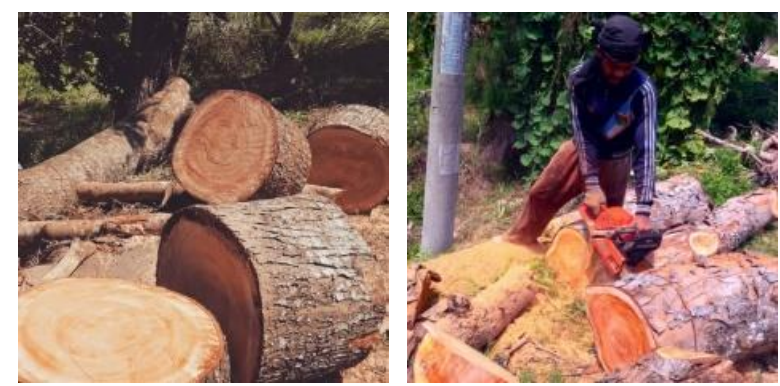

Foto 2. Proses pemotongan kayu Kayu yang di pilih Al Custom Drum

(dok.2020. Alfin Duma Felanda)

Proses pemotongan kayu yang di lakukan oleh salah satu karyawan Al Custom Drum untuk membuat instrumen Snare Drum, pada tahap setelah penebagan pohon kemudian kayu langsung dipotong potong menjadi beberapa bagian karena dalam satu kayu utuh dapat menjadi satu set instrumen Drum. Tahap selanjutnya merupakan tahap pemotongan bagian samping kayu menjadi segi lima agar memudahkan saat proses selanjut nya serta mempercepat dalam proses pengeringan oleh karena kayu sudah tidak tertutupi oleh kulit. Dalam tahap ini kayu akan terlihat motif seratnya karena proses pemotongan samping kayu, hal ini juga yang menjadi menarik karena menjadi motif alami kayu yang akan di jadikan sebuah instrumen Snare Drum akan terlihat natural. Setelah proses pemotongan kemudin kayu akan di diamkan terlebih dahulu atau di anginaanginkan untuk sedikit menugrangi kadar air yang terdapat pada kayu dari Al Custom Drum, kayu yang sudah di nyatakan cukup kemudian di lakukanlan proses pelubangan tengah untuk menjadikanya shell dari instrumen Snare Drum hal ini yang di lakukan oleh rumah produksi $\mathrm{Al}$ Custom Drum proses pemotongan kayu guna memperoleh hasil yang bik. Berikut gambar proses pemotongan kayu oleh Al Custom Drum:

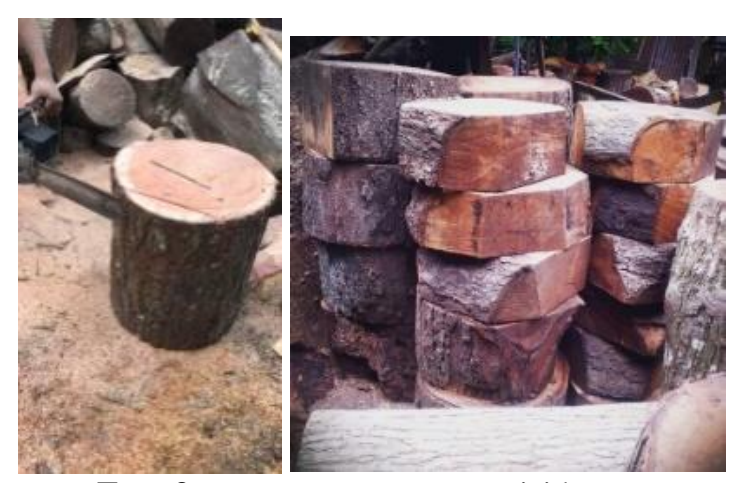

Foto 3. Proses pemotongan sisi kayu (dok.2020. Alfin Duma Felanda)

\section{Proses Pengeringan Kayu}

Proses pengeringan kayu merupakan proses untuk mengurangi kadar air yang berada di dalam kayu guna menjadikan kayu lebih kering. Pada tahap pengeringan ini digunakan oleh karena setelah tahap pembubutan kayu masih memeliki kadar air yang lumayan banyak sehigga proses selanjutnya merupakan pengeringan guna mengurangi kadar air di dalam kayu. Pada pembuatan instrumen Snare Drum yang di lakukan oleh rumah produksi $\mathrm{Al}$ Custom Drum proses pengeringan di bagi menjadi dua tahap pengeringan yaitu pengeringan secara manual dan menggunakan oven.

Pengeringan manual merupakan prose pengeringan yang memanfaatkan panas matahari dalam proses pengeringanya, Hal inilah yang di lakukan oleh $\mathrm{Al}$ Custom Drum pada tahap proses pengeringan manual. Berdasarkan hasil wawancara dengan narasumber Alfin Duma proses pengeringan dari awal hingga tahap siap untuk dibubut memerlukan waktu enam bulan, karena menurut Alfin kayu yang sudah dikeringkan dengan waktu enam bulan sudah berkurang sekitar $30 \%$ dari kadar air yang dimiliki sehingga kayu siap menuju tahap selanjutnya. Hal ini sesuai dengan teori mebuatan instrument musik yang berdasarkan kualitas bahan kayu akan mempengaruhi hasil ahir isntrumen.

\section{Proses pembubutan kayu oleh Al Custom Drum}

Pembubutan, merupakan proses dalam membentuk kayu menjadi diameter yang di inginkan dengan proses pembubutan kayu akan diolah menjadi bentuk tabung dengan menggunakan mesin bubut. Dalam proses 
pembuatan instrumen Snare Drum yang dilakukan oleh $\mathrm{Al}$ Custom Drum memiliki beberapa tahap yaitu bubut bagian luar dan bubut bagian dalam.

Proses pembubutan bagian luar kayu

Pembubutan bagian luar kayu merupakan tahap awal dari pembubutan yang dilakukan oleh rumah produksi Al Custom Drum, pada tahap ini kayu yang masih berbutuk segilima kemdian di bubut pada bagian luar guna mendapatkan bentuk tabung yang lebih halus, dalam tahap ini $A l$ Custom Drum proses bubut yang dilakukan hanya menggurangi bagian luar kayu hingga terpisah antara kayu dan kulitnya yang berkisar dua sampai tigas sentimeter. Hal ini yang dilakukan oleh Alfin untuk mempercepat pengeringan karena kayu sudah terpisah seutuhnya denga kayu. Berikut ini merupakan foto dari proses pembubutan yang di lakukan oleh Al Custom Drum. Berikut gambar Proses pembubutan yang dilakukan oleh $A l$ CustomDrum:

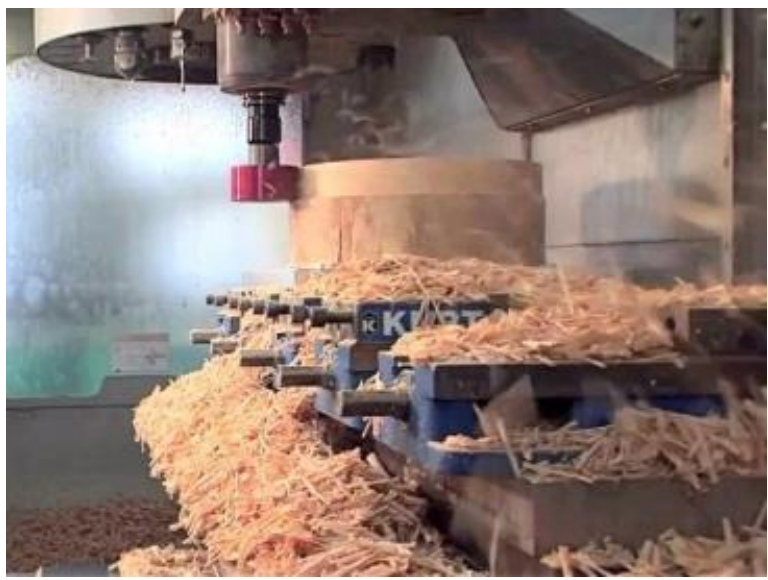

Foto 4. Proses pembubutan yang di lakukan oleh $A l$ Custom Drum

(dok.2020 Alfin Duma Felanda)

Pembubutan pembentukan lubang tengah pada kayu. Pembubutan pembentukan lubang tengah pada kayu merupakan proses pembentukan lubang dibagian dalam kayu guna memberikan diameter lingkaran bagian dalam untuk menjadi bentuk instrumen Snare Drum yang sesuai dengan desain yang dibuat, tahap pembentukan lubang tengah ini dikerjakan oleh Al Custom Drum dengan waktu 2 sampai 3 hari. Proses ini merupakan tahap bubut setengah jadi dari bahan sheel instrumen Snare Drum. Berikut gambar

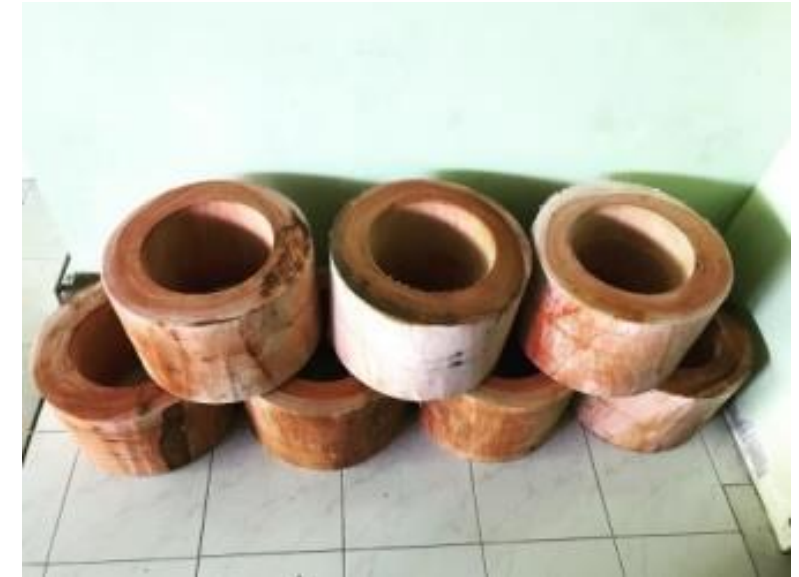

Foto 5. Hasil pembentukan lubang tengah pada kayu yang di lakukan oleh Al Custom Drum (dok.2020 Alfin Duma Felanda)

Tahap selanjutnya yaitu tahap pengeringan menggunakan oven agar kayu yang sudah dibubut setengah jadi memiliki warna yang yang lebih merah dari hasil pembakaran dan mengurangi kadar air.

\section{Pengeringan dengan Oven}

Pengeringan menggunakan oven ini di lakukan kurang lebih membutuhkan waktu 1-2 jam yang di lakukan oleh $\mathrm{Al}$ Custom Drum, seperti pada gambar di bawah ini adalah proses pengovenan yang di lakukan oleh Al Custom Drum. Pada proses ini kayu di masukan kedalam tungku yang berukuran besar kemudian di lakukan proses pengovenan. Penggunaan alat pengukur suhu sangat penting karena dari pengukur suhu, akan mengetahui seberapa tingkat panas yang di hasilkan oleh oven oleh proses pembakaran yang dilakukan. Tungku yang digunakan oleh rumah produksi Al Custom Drum masih menggunakan tungku tradisional. Setelah proses pengeringan yang di lakukan maka kayu akan berwarna lebih matang (kecoklatan) dan kadar air yang di miliki sudah berkurang seperti gambar di bawah ini.

Martawijaya et al.
menyarankan menggunakan skedul
pengeringan dengan
pengeringan $43-76^{\circ} \mathrm{C}$ dengan
kelembaban relatif $75-33 \%$. Hasil
observasi langsung di industri
pengolahan kayu, pengeringan
dengan mengacu skedul yang
dijelaskan oleh Martawijaya et al.
(2005) dengan ketebalan $40-60 \mathrm{~cm}$.

Pengeringan dengan suhu 45- 70C di gunakan agar kayu tidak menjadi gosong atau terbakar karena proses pengentin ini hanya bertujuan untuk memberikan warna coklat dan sedikit mengurangi kadar air. Hal ini juga yang di 
lakukan oleh rumah produksi $\mathrm{Al}$ Custom Drum dalam mengeringan kayu dengan menggunakan oven serta dengan suhu 70 derajat untuk mengurangi kadar air dan juga memberikan warna merah pada kayu karena hasil oven. Berikut gambar proses pengovenan kayu oleh $A l$ Custom Drum:
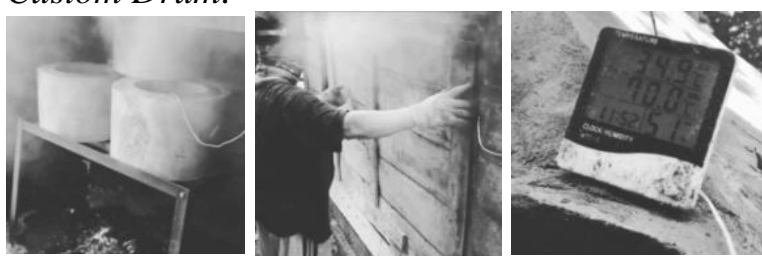

Foto 6. Proses pengovenan kayu oleh $\mathrm{Al}$ Custom Drum

(dok.2020 Al Custom Drum)

\section{Pembubutan Barang jadi Bahan Kayu Mahogani}

Pembubutan tahap ini merupakan pembubutan tahap ke dua di mana tahap kedua ini menjadikan material instrumen Snare Drum menjadi bentuk yang di inginkan dengan ketebalan kayu serta tinggi yang di inginkan, biasanya ketebalan yang di gunakan dalam rumah produksi Al Custom Drum yaitu antara $3-5 \mathrm{~cm}$ dan tinggi tergantung pesanan biasanya untuk snare standart tingginya adalah 5 inch- 9 inch. Dalam proses pembubutan barang jadi ini proses pengerjaanya membutuhkan waktu kurang lebih 1 hari. Berikut gambar proses pembubutan dan hasil dari tahap ke dua pembubutan oleh $A l$ Custom Drum:

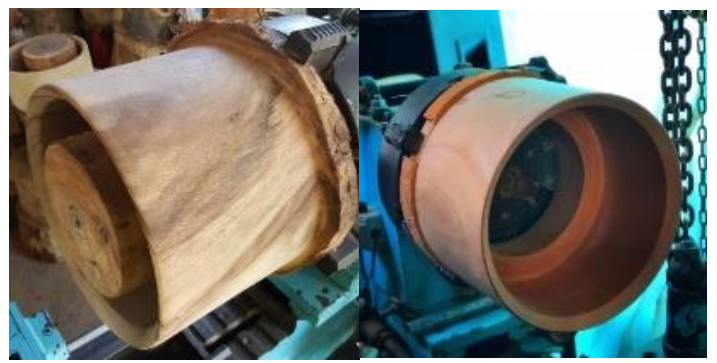

Foto 7. Proses pembubutan tahap dua oleh Al Custom Drum

(dok.2020 Alfin Duma Felanda)

Setelah selesai pembubutan yang di lakukan akan di jemur kembali secara manual menggunakan panas matahari bertujuanya untuk mengurangi kadar airnya.

\section{Pemberian Minyak Bahan Kayu Mahogani}

Pemberian minyak kayu pada tahap ini bertujuan agar kayu memiliki ketahan yang lama sehingga kayu tidak mudah lapuk. Pemberian minyak kayu dilakukan pada seluruh sisi kayu dengan merata. Setelah pemberian minyak pada kayu kemudian di keringkan kembali dengan cara di jemur di bawah sinar matahari, hal ini merupakan proses pengeringan dari tahap bahan kayu ahir sebelum finising warna/ pengecatan. Berikut gambar pemberian minyak kayu yang dilakukan oleh Al Custom Drum:

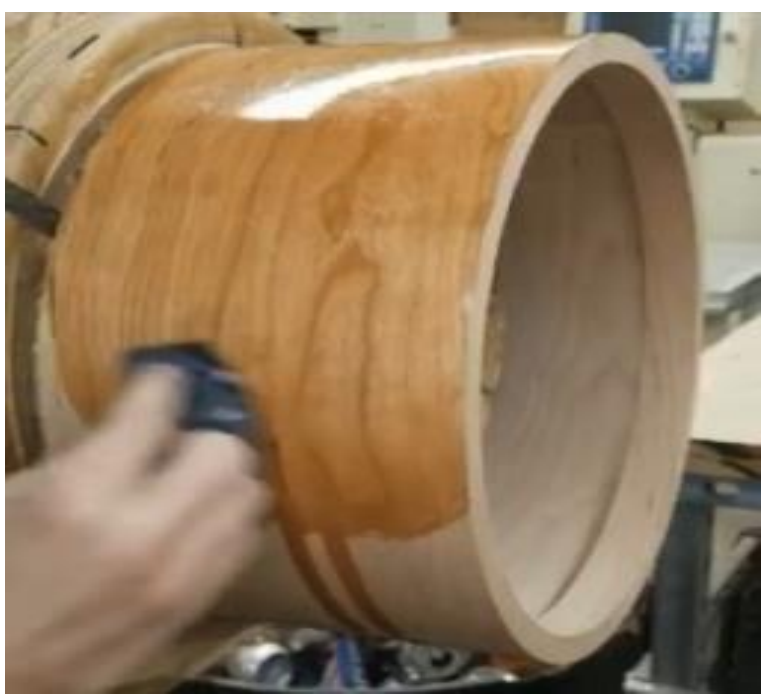

Foto 8. Pemberian minya kayu oleh Al Custom Drum (dok.2020 Alfin Duma Felanda)

Proses finishing instumen Snare Drumoleh Al Custom Drum

Proses finishing merupakan proses pewarnaan pada instrument Snare Drum yang sudah selesai melalui tahap pembubutan, hal ini dilakukan agar instrumen Snare Drum memiliki hal yang menarik dari segi tampilan atau visual, dengan adanya pewarnaan yang bagus instrumen Snare Drum akan memiliki nilai lebih dari segi visualnya, hal ini juga di lakukan oleh rumah produksi Al Custom Drum pada tahap pemberian warnaan yang dilakukan sesuai dengan permintaan dari pembeli instrumen Snare Drum, akan tetapi jika instrumen Snare Drum bukan merupakan pesanan warna yang di berikan merupakan ide dari pemilik Al Custom Drum yaitu Alvin Duma. Dalam proses untuk pemberian warna pada rumah produksi $A l$ Custom Drum membutuhkan waktu kurang lebih dua minggu untuk mengerjakan. Menurut Alfin Duma, pemberian warna membutuhkan waktu dua minggu di karenakan kayu tidak mudah untuk di cat jadi prosesnya berlapis dan juga proses pegeringan yang cukup juga di perlukan agar cat bisa kering dengan sempurna. Hal ini juga merupakan dari penciptaan hasil yang menarik sehingga memberikan nilai lebih dalam visual yang diciptakan.

\section{Pemberian cat dasar}

Proses pemberian cat dasar merupakan lapisan pertama yang dilakukan saat pengecatan kayu hal yang di lakukan pemberian dempul dan 
filler. Fungsi adalah untuk menambal lubang pori pori kayu , sedangkan dempul untuk menutup warna natural pada kayu untuk finishing warna non natural, proses pengecatan pada lapisan dasar yang di lakukan oleh $\mathrm{Al}$ Custom Drum menggunakan cat semprot, karena menurut dari Alfin sendiri penggunaan cat semprot mempercepat proses pengecatan dan mendapatkan detail hasil dari pengecatan yang bagus, sedangkan untuk proses pengerjaanya sendiri pada tahap dasar ini memerlukan waktu kurang lebih 1 hari untuk pengerjaan proses pengecatan serta 2 hari untuk pengeringan.

Cat premier atau lapisan utama

Cat premier memiliki fungsi yang hampirsama dengan sealer yaitu membantu fungsi cat dasar seperti menutup pori-pori kayu serta mempersiapkan lapisan untuk aplikasi cat warna untuk pengecatan lapisan utama yang dilakukan oleh rumah produksi Al Custom Drum yaitu dua kali pengecatan hal ini dilakukan agar pori-pori kayu dapat tertutupdengan sempurna sehingga untuk chat selanjutnya cat tidak meresap kedalam pori-pori kayu serta pada tahap ini memerlukan waktu 4 hari untuk proses pengerjaanya sehingga cat kering dengan sempurna.

Cat warna

Cat warna merupakan pemberian warna yang di lakukan pada instrument Snare Drum bisa berwarna merah, biru, kuning, hijau dan lain-lain, pewarnaan ini juga menentukan menarik atau tidaknya visual dari sebuah instrumen Snare Drum yang di produksi oleh $A l$ Custom Drum. Dalam proses pewarnaan ini rumah produksi Al Custom Drum memerlukan waktu kurang lebih 4 hari pengerjaan sampai cat benar benar kering dan menempel pada kayu dengan sempurna.

Coating

Coating merupakan proses tahap ahir dari pengecatan yaitu memberikakan lapisan ahir untuk melindungi lapisan sabelumnya, biasanya lapisan ini akan memberi efek berupa berkilau sehingga instrument Snare Drum produksi $A l$ Custom Drum yang sudah selesai tahap pewarnaan menjadi lebih tahan lama. Sedangkan untuk tahap ahir ini $A l$ Custom Drum memerlukan proses pengerjaan tiga hari untuk finising dari proses pengecatan. Berikut proses pengecatan dan
Managemen Pemasaran Rumah Produksi
Instrumen $\mathrm{Al} \mathrm{Custom} \mathrm{Drum} \mathrm{di} \mathrm{Desa}$ Minggiran Kecamatan Papar Kabupaten Kediri

Managemen merupakan sebuah sistem yang diciptakan dan dijalankan untuk membuat perencanaan, pengorganisasian, penempatan, pengarahan dan pengawasan untuk keberhasilan tujuan yang diinginkan. Hal ini juga dilakukan pula oleh rumah produksi Al Custom DrumDrum yaitu dengan menciptakan satu sistem managemen untuk menunjang produksi instrument dan juga sistem pemasarannya.

Sistem produksi yang digunakan dalam rumah produksi $A l$ Custom DrumDrum merupakan hasil keputusan yang dilakukan oleh Alfin Duma Felanda selaku pemilik usaha Al Custom Drum dalam mengelola 2 (dua) staf karyawan. Selain oleh karena Alfin merintis usaha produksi alat musik dari awal secara mandiri, hal ini juga dilakukan juga untuk selalu menciptakan kualitas dan harga jual dari alat musik yang produksi. Sehingga baik perencanaan, pengorganisasian, penempatan, pengarahan dan pengawasan produksi selalu dijalankan dilakukan oleh Alfin sendiri.

Alfin melakukan perencanaan produksi alat musik berdasarkan kriteria alat musik yang diinginkan oleh pembeli, yaitu dengan system selalu aktif melakukan komunikasi kepada pembeli, baik melalui media yang digunakan untuk pemasaran (Instagram) ataupun melalui media komunikasi Washaap milik Alfin sendiri. Dari komunikasi secara langsung yang dilakukan oleh Alfin inilah kemudian baru proses perencanaan produksi alat musik baru mulai dilakukan. Setekah perencanaan produksi alat musik dilakukan, kemudian para karyawan mengerjakan apa yang telah direncakaan melalui pengelolaan dan juga pengawasan yang dilakukan oleh Alfin. Hal inilah sebagai dampak keberhasilan dari sistem menejemen pemasaran yang dilakukan oleh Rumah produksi Al Custom. Menejemen Pemasaran Rumah Produksi Al Custom Drum

Pamasaran merupakan sebuah cara untuk menjual suatu barang dengan metode dan tehnik penjualan sesuai dengan spesifikasi barang yang akan di jual, setiap pemilik usaha memiliki cara marketingnya masing masing dengan menyasar pasar yang mereka inginkan dengan produk mereka, dalam hal ini adalah cara Alcustom untum memasarkan Snare Drum yang di produksi

\section{Rencana pemasaran}

Rencana pemasaran merupakan hal utama yang harus di lakukan dalam proses pemasaran, rencara yang matang serta ketepatan dalam perencanaan sangan di perhitungkan demi 
suksesnya sebuah pemasaran produk dalam hal ini Alcustom drum merencanakan pemasaran yang meliputi sasaran pasar dan juga dan kebutuhan akan instrument Snare Drum, dalam perencaaan pemasaran yang di lakukan oleh Alfin melihat beberapa aspek yaitu

\section{Analisis pasar}

Analisis pasar merupakan langkah meneliti tentang situasi dan kondisi kebutuhan pasar dengan mempertimbangkan peluang, keunggulan produk yang di miliki, guna memasarkan produk yang di miliki serta target pasar yang di inginkan. Langkah analisa pasar juga dilakukan oleh Alfin terhadap maraknya perkembangan grub band beserta acara pertunjukan musik band dikalangan masyarakat Kediri. Alfin menjelaskan bahwa semua para pelaku musik band selalu berkeinginan untuk memainkan alat yang bagus, namun hal tersebut jarang bisa terjadi. Oleh karena kemampuan para pemusik band serta kemampuan penyelenggaraan acara musik di Kabupaten Kediri (wawancar 10 April 2020). Dari analisis ini disimpulakan bahwa kebutuhan pasar industri alat musik di Kabupaten Kediri sangat diharapkan dapat memenuhi kebutuhan terhadap para pemain musik khusuya musik jenis Band. Hingga akhirnya timbul niatan untuk dapat merencanakan produksi alat musik khususnya alat musik Snare Drumdengan kualitas yang bagus namun masih dengan harga yang masih terjangkau, serta dapat dimainkan dengan lintas genre musik. Hasil dari analisis yang dilakukan menciptakan peluang untuk merencanakan produksi alat musik sebagai permintaan kebutuhan pasar musik di Kabupaten Kediri.

\section{Produk peraga untuk promosi}

Produk peraga merupakan penciptaan produk sebagai sebuah cara untuk menujukan hasil produk antara lain tentang keunggulan dan ciri khas barang yang dipromosikan. Langkah ini bertujuan untuk menarik minat dari pasar (pembeli). Al Custom Drum membuat produk peraga sebagai ajang promosi dari instrument Snare Drumyang diproduksi. Hal ini dilakukan untuk menunjukan tentang ciri khas instrument yang dibuat secara utuh (true solid wood) dan dengan menggunakan bahan jenis kayu Mahogani. Instrumen Snare Drumsebagai produk peraga kemudian di dokumentasikan melalui media foto dan video serta kemudian dipromosikan menggunakan media sosial yaitu instagram.

Rumah produksi Al Custom Drum melakukan promosi dengan mengunggah foto- foto instrument Snare Drumyang di produksi melalui akun instagram AlcustomDrum. Fotofoto yang memperlihatkan dari chiri khas keutuhan kayu dapat menjadi presentasi tentang pemikiran akan karakter suara nyaring (renyah) dan tidak pecah (ulem) dari instrumen yang diproduksi. Langkah ini sangat efektif oleh karena para peminat sudah dapat menginterpretasikan secara mandiri dari tampilan foto yang diunggah. Berikut foto instrument Snare Drumberbahan kayu utuh yang diunggah dalam akun instagram AlcustomDrum oleh Alfin:

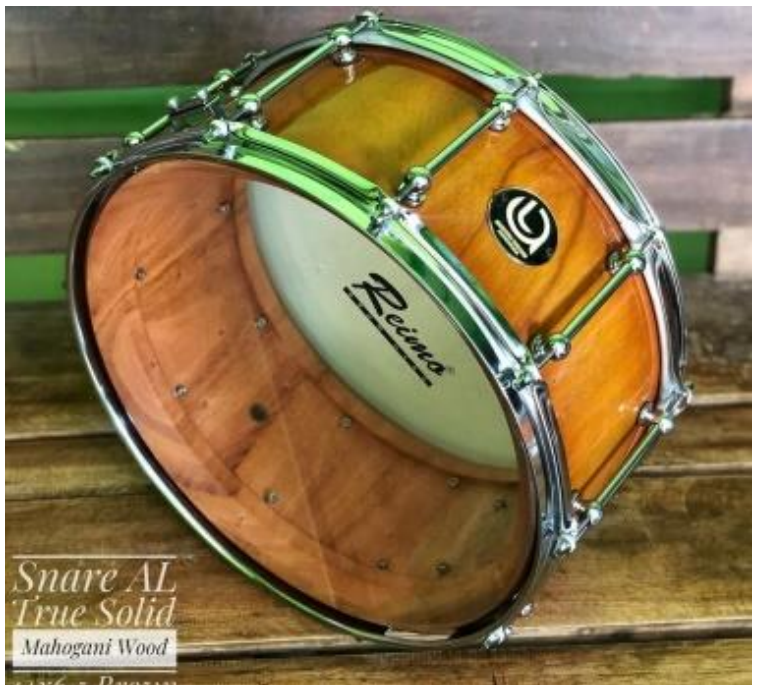

Foto 9. foto instrument Snare Drum berbahan kayu utuh yang diunggah dalam akun instagram $\mathrm{Al}$ custom Drum (dok.2020 Alfin Duma Felanda)

Rumah produksi Al Custom Drum juga memperlihatkan tampilan (visual) instrument Snare Drummelalui foto-foto yang diunggah antara lain tampilan warna dan motif sebagai finishing instrumen, keindahan dan kerapian dari alat yang di produksi. Langkah ini juga sangat menarik oleh karena tampilan foto dikerjakan dengan serius. Sehingga dapat menarik perhatian pembeli. Berikut foto instrument Snare Drumyang di unggah dalam media social instagram Al Custom Drum: 


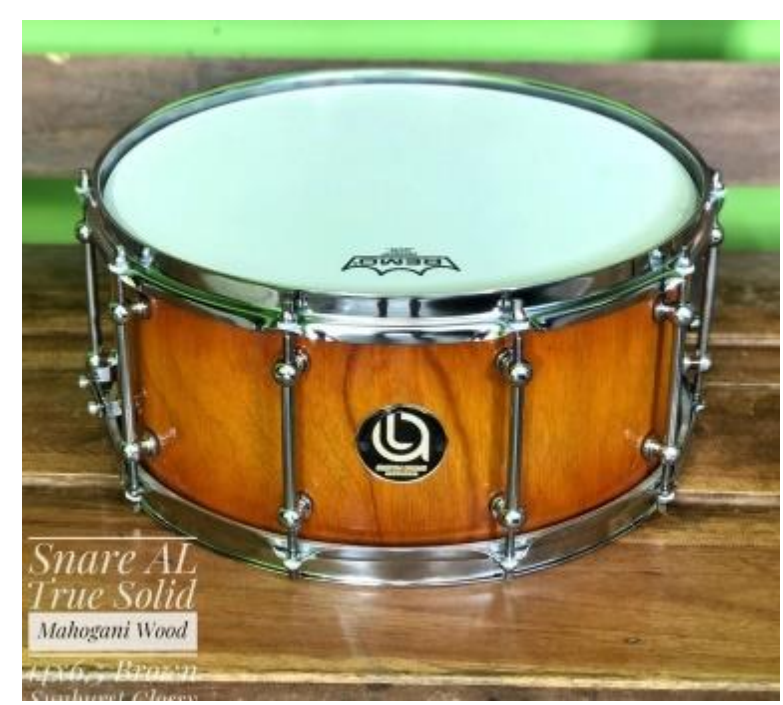

Foto 10. Foto yang di unggah pada Instagram oleh $A l$ Custom Drum

(dok.2020 Alfin Duma felanda)

\section{Video Instrumen Snare Drum produksi Al Custom Drum}

Rumah produksi Al Custom Drum juga mendokumentasikan produk peraga instrument Snare Drum dengan menggunakan media audio visual format video. Video tersebut digunakan sebagai media untuk mempresentasikan karakter suara instrument yang diproduksi melalui sajian alat Snare Drumdengan menggunakan tehnik roll dan rimshot.

Teknik roll dan rimshot sangat dominan dalam sajian instrument Snare Drum. Sehingga penggunaan tehnik roll di gunakan untuk menunjukan karakter suara yang kempal dan tidak pecah (ulem) serta nyaring (renyah). Sedangkan tehnik rimshot digunakan untuk menunjukan karakter suara keras. Penggunaan video untuk mendokumentasikan instrument porduk peraga sangat efektif dalam rangka promosi instrument Snare Drumyang diproduksi oleh Al Custom Drum. Hal ini ditunjukan dengan banyaknya tanggapan dan ulasan mengenai ketertarikan terhadap instrument Snare Drumyang di unggah dalam video. Perkembangan dari ketertarikan tersebut kemudian pihak pembeli melakukan komunikasi lebih lanjut melalui media Whatsapp milik Alfin. Berikut gambar video tampilan produk peraga dan tanggapan dari calon pembeli dalam media social Al custom Drum:

Strategi pemasaran

Strategi pemasaran merupakan cara yang di gunakan untuk memasarkan produk yan di miliki sehingga menjadikanya tepat sasaran seusai pasar yang ingin di tuju. Dalam rumah produksi Al Custom Drum strategi yang di gunakan meliputi, tujuan pemasaran, strategi, jadwal pelaksaanaan, anggaran pemasran, control. Hal ini di gunakan dalam menunjang efektifitas pemasaran yaitu luas jangkauan pemasaran, wilayah pemasaran. Berikut strategi pemasaran oleh Al Custom Drum:

\section{Tujuan pemasaran}

Tujuan pemasaran Al Custom Drum yaitu untuk memasarkan produk instumen Snare Drumberkualitas dengan menggunakan jenis kayu lokal (Mahogani) dan dibuat dengan keutuhan bahan kayu (true solid wood) serta dengan harga yang masih terjangkau. Tujuan ini merupakan hasil analisa yang di lakukan oleh Alfin selaku pemilik dan sekaligus pembuat alat dikalangan pemusik instrument Drum di Kabupaten Kediri. Sehingga merumuskan niat untuk membuat alat musik Snare Drumyang berkualitas namun masih dengan harga jual yang terjangkau oleh para pemusik local. Instrumen Snare Drummenjadi salah satu alat musik yang sering diadakan secara mandiri oleh para pemusiknya, sehingga memproduksi alat ini akan bertujuan juga untuk mendukung gaya (style) para pemusik instrument Drum.

Strategi

Strategi pemasaran yang di lakukan oleh $A l$ Cutom Drum yaitu memanfaatkan sarana media social sebagai strategi yang utama dalam pemasaran produk instrument Snare Drum. Hal ini oleh karena begitu maraknya masyarakat menggunakan media social misalkan media instagram dan media whatsapp. Alfin juga pernah menggunakan media social Facebook sebagai media pemasaran. Namun oleh karena perkembangan pengguna Facebook dikalangan para pemusik mulai menurun dan beralih menggunakan media Instagram maka Alfin memilih untuk kemudian focus menggunakan strategi pemasaran melalui media Instagram.

Strategi pemasaran dengan menggunakan media Instagram sangat efektif terhadap dampak keberhasilan pemasaran instrument Snare Drum. Hal ini disebabkan selain maraknya para pemusik menggunakan media Instagram juga oleh karena media ini dapat digunakan untuk mempresentasikan produk instrument baik berupa dokumen foto, video dan diskripsi dari produk.

Media Instagram juga dapat digunakan untuk melakukan pembicaraan baik melalui bentuk tulisan (chating), melalui telepon video (videocall) ataupun memuat ulang (repost) unggahan baik berupa foto ataupun video yang 
dilakukan oleh pembeli. Dari maraknya pengguna media Instagram berserta fasilitas yang maksimal maka rumah produksi Al Custom Drum melakukan strategi pemasaran dengan menggunakan media social Instagram dengan nama akun AlcustomDrum. Berikut gambar instrument Snare Drumproduksi Al Custom Drum berserta pembeli instrument Snare Drumproduksi Alcustom Drum.

\section{PENUTUP}

Kesimpulan merupakan hasil rangkuman penelitian dari pembahsan yang dapat disimpulkan dari pemabahasan tentang organology Snare Drumyang diproduksi oleh Al Custom Drum sebagai berikut: Al Custom Drum merupakan rumah produksi instrument alat musik yang terletak di Desa Minggiran Kabupaten Kediri Propinsi Jawa Timur. Dengan chiri khas yang dimiliki yaitu bahan kayu local mahogany dengan keutuhan kayu (true solid wood) sehingga kayu jenis ini dapat di gunakan menjadi Instrumen Snare Drumyang dapat digunakan beberapa genre musik. pemilik rumah produksi Al Custom Drum yaitu Alfin Duma Felanda juga merupakan seorang drummer sehingga hal ini menjadikanya nilai lebih dalam menialai Instrumen Snare Drumdan berdasarkan pengalamanya dalam bermain drum dengan berbagai merk Drum inilah yang juga menjadi revrensi bunyi untuk membuat sebuah Snare Drum.

Organologi dari instrument alat musik Snare Drumproduksi Al Custom Drum menggunakan bahan kayu local mahogany dengan proses produksi dari tahap awal hingga ahir dengan estimasi waktu 18 hari pengerjaan untuk kemudian menjadi instrument Snare Drumyang sudah dapat dimainkan, bahan kayu local dengan jenis mahogani yang dipilih menciptakan karakter instrumen Snare Drumyang nyaring (renyah) dan tidak pecah (ulem).

Rumah produksi Al Custom Drum juga memiliki chiri khas dari produksinya yaitu sudut boring yang dilakukan pada saat proses bubut, dengan mempertimbangkan pembuatan dengan sudut tertentu menjadikanya berbeda dari rumah produksi yang lain.

Managerial dari rumah produksi Al Custom Drum yang meliputi pemasaran produk dengan menggunakan media social Instagram dan Whatsaap untuk memasarkan produk dan berkomunikasi serta melakukan pembayaran dengan sistem transfer melalui nomor rekening milik Alfin, dari meagerial seperti ini sangat efisien digunakan untuk mempermudah pemasaran serta proses transaksi yang dilakukan. Sistem pemasaran yang dilakukan oleh rumah produksi Alcustom Drum menggunakan beberapa strategi dalam memasarkan produknya guna menjadikanya tepat sasaran pasar dan hal ini sangat efisien di lakuakan sehingga ada imbal balik dari setrategi yang digunakan dengan hasil yang diterima dengan bertambahnya pesanan terhadap Instrumen Snare Drumproduksinya serta penggunan jasa pengiriman juga mempermudah dalam proses pengiriman produk.

Berdasarkan dari hasil penelitian, pembahasan dan kesimpulan peneliti memberikan saran yang bertujuan untuk kebaikan dan kemajuan rumah produksi Al Custom Drum sebagai berikut: Dengan seiring kemajuan tehnologi dan perekonomian rumah produksi Al Custom Drum menambah strategi nya dalam hal promosi dengan mengikuti pameran alat musik guna lebih mengenalkan produknya terhadap publik. Untuk meningkatkan layanan terhadap produksi yang dilakukan dengan vareasi snare yang lebih banyak lagi tetapi tetap mempertimbangkan kebutuhan pasar dan perkembangan kebutuhan pasar akan Snare Drum yang di inginkan. Pada saat rumah produksi sudah berkembang lebih besar peneliti menyarankan untuk menggunakan media pemasaran yang lain seperti Shoppe, Tokopedia, dan Buka lapak dan kemudian dicantumkan alamat toko onlintersebut pada informasi di Instagramnya, guna memberikan kepercayaan lebih terhadap pembeli, karena dengan menggunakan media pemasaran seperti diatas yaitu akan melalui proses pembayaran melalui pihak ke 3 guna untuk menghindari proses penipuan pembayaran oleh customer.

\section{DAFTAR PUSTAKA}

Hendarto Sri (2011) Organologi dan Akustika I \& II, Hendarto, Sri., Bandung: Lubuk Agung,

Hardjana, Suka (2018) Estetika Musik Sebuah Pengantar, Hardjana, Suka, Yogyakarta : Mantrijeron,

Sugiono (2010) Metode Penelitian Kuantiitatif, Kualitatif, dan R\&D, Sugiono., Bandung: Gegerkalong Hilir,

AJD Denny (2003) Panduan Praktis Bermain Drum Untuk Tingkat Menengah Sampai Tingkat Mahir, AJD Denny., PT Gramedia Widiasarana Indonesia, Ismawardi, I. (2012). Gitar Custom Ibanez PGM Produksi Mirai di Cakalang V Makassar 
(Suatu Tinjauan Organologi), Jurnal

Doctoral dissertation,FSD)

Banoe, P. (2003). Kamus musik. Kanisius.

Sungkar, Ossa (2006). Panduan Bermain Drum

Untuk Pemula, Sungkar Ossa.,Jakarta

Philosophia Sakriwasista, B. I. M. A. (2017).

Travel Cajon Oleh 'Arka Cajon'sidoarjo

(Struktur Organologi Serta Teknik

Pembuatan). APRON Jurnal Pemikiran

Seni Pertunjukan, 1(11).

Setiawan, M. A. (2018). Proses Pembuatan Djembe

oleh Purwanto (Doctoral dissertation,

INSTITUT SENI INDONESIA

SURAKARTA).
Nazmei Sari Nindia (2019). "Musik

Angklungpaglakdesakemiren

Banyuwangi." Jurnal Pemikiran Seni

Pertunjukan.

Raden Mutia Inayah Azzahra (2018)

AnalisisMorfofisiologisMahogani

(swietenia macrophylla King) unhas.ac.id

Mashudi (2016). Keragaman pertumbuhan mahogany daun lebar (swietenia macrophylla King) dari dua populasi di Yogyakarta Jurnal Penelitian Hutan

Masruroh, D. (2017). Alat Musik Kolintang Produksi "Irama Nusantara" Di Desa Pesapen Kecamatan Wiyung Surabaya (Kajian Organologi). Solah, 7(1). 